\title{
Performance assessment of stacked air-cathode microbial fuel cells under series and parallel electrical connections
}

\author{
Simona Di Micco ${ }^{1,}$, Pasquale De Falco ${ }^{1}$, Mariagiovanna Minutillo ${ }^{2}$, Antonio Bracale ${ }^{1}$, Pierluigi Caramia ${ }^{1}$, Angelo \\ Gifuni $^{1}$, Giuseppe Grassini ${ }^{1}$
}

${ }^{1}$ Univerisity of Naples "Parthenope", Naples, Italy

${ }^{2}$ Department of Industrial Engineering, University of Salerno, Salerno, Italy

\begin{abstract}
Microbial fuel cells (MFCs) are playing an important role in the context of sustainable energy development. They represent a sustainable approach to harvest electricity from biodegradable materials. However, harvesting energy from MFCs represents a critical issue because of the low output voltage and power produced. Realizing stacked configurations may involve an increase in MFCs performances in terms of output voltage, current and electric power.

In this paper, two stacked configurations under different electrical connection modes have been designed, developed, modeled and tested. The stacked MFCs consist of 4 reactors $(28 \mathrm{~mL} \times 4)$ that are connected in series, and parallel-series modes. Three different tests have been carried out, which involves: 1) performing the polarization and power curves by applying decreasing resistances; 2) assessment of the electric behavior of each reactor over time at a fixed resistance, 3) performing the polarization and power curves by applying increasing resistances. Moreover, a numerical model for predicting the transient behavior of the electrical quantities for one reactor, has been developed and validated by using the experimental data. As expected, the results highlighted that the parallel-series configuration assures the highest volumetric power density compared to the series configuration, reaching the maximum value of $1248.5 \mathrm{~mW} / \mathrm{m}^{3}(139.8 \mu \mathrm{W})$ at 0.291 $\mathrm{mA}$. Eventually, by comparing the numerical and the experimental data, it has been demonstrated that the developed model is able to predict the reactor's electrical trend with a good accuracy.
\end{abstract}

\section{Introduction}

MFCs represent a sustainable approach to harvest electricity from biodegradable materials. Thanks to the capability of bacteria inside the reactor of generating electricity while consuming organic matter, the can be considered as a future option for the treatment of organic wastes, bioremediation, and the recovery of bioenergy from wastes [1-5]. However, harvesting energy from MFC represents a critical issue because of the low output voltage and power produced, which limits its use as an electricity supply system and its development on the market as renewable energy technology[6-8].

The scale-up of MFCs does not represent a valid solution for improving the MFCs performances since the greater distance between the electrodes, that can occur in bigger reactors, involves a reduction in power density.

In a previous paper [9], the authors demonstrated that increasing the reactor volume and using multiple anodes did not involve an improvement in performances because of the negative influence of the greatest geometric parameters, i.e. the ratio between anodic and cathodic surfaces, the electrodes spacing, etc.
On the other hand, realizing stacked MFCs configurations, according to different electrical connection modes, may feature a more feasible and efficient strategy for improving the performances. As matter of fact, realizing stacked MFCs in series mode allows increasing the output voltage with respect to a single cell as well as realizing stacked MFCs in parallel mode, which allows to increase the output current compared to the single MFC.

Estrada-Arriaga et al. [10] studied two different aircathode stacked microbial fuel cells configurations connected in series for municipal wastewater treatment and electricity generation. The first stack (20 individual air-cathode MFCs) was able to produce a maximum power density of $79 \pm 0.65 \mathrm{~mW} / \mathrm{m}^{2}$; the second stack (40 aircathode MFCs), was characterized by a power production of $4.2 \pm 0.6 \mathrm{~mW} / \mathrm{m}^{2}$.

Ieropulos et al. [11] tested the polarization curves trends of 10 identical MFCs connected in series, parallel and series/parallel configurations. Results highlighted that volumetric power densities were $0.45 \mathrm{~W} / \mathrm{m}^{3}, 0.81 \mathrm{~W} / \mathrm{m}^{3}$, $0.56 \mathrm{~W} / \mathrm{m}^{3}$, for the series, parallel and series/parallel configurations, respectively.

Wang et al. [12] analyzed 4 MFCs electrical connections modes: series, parallel, series/parallel and parallel/series.

\footnotetext{
* Corresponding author: simona.dimicco@studenti.uniparthenope.it
} 
Results, in terms of power outputs $(\mathrm{mW})$ were $4.02( \pm$ $1.01), 6.84( \pm 0.24), 4.58( \pm 0.30)$, and $5.64( \pm 0.96)$ for the series $(6$ cells), parallel ( 5 cells), series/parallel ( 5 cells) and parallel/series ( 5 cells) connections, respectively.

In a previous paper [13], the authors tested 4 different configurations demonstrating that the best performances were measured for the parallel-series configuration.

Starting from these results, in this paper the authors study in depth the electrical behavior of two of these configurations, one which maximizes the output voltage (i.e series-configuration) and the other one which maximizes the volumetric power density (i.e parallelseries configuration). In particular, the polarization curves have been measured by applying both the conventional and the "inverse" monocyclic method, with a sampling time of 9 minutes.

Different experimental tests have been carried out: Test 1 which involves performing the polarization and power curves by applying decreasing resistances; Test 2 in which the assessment of the electric behavior of each reactor over time at a fixed resistance is evaluated; Test 3 which implies performing the polarization and power curves by applying increasing resistances.

Furthermore, in order to predict the transient behavior of the electrical quantities, a numerical model has been developed and validated by using the experimental data. During these tests, the rector's electrical behavior has been evaluated skipping from the OCV condition to the maximum power one.

\section{Material and Methods}

The experimental activities have involved, first of all, the design and the development of the reactors as well as the substrate preparation, the biofilm growth, and the bacteria acclimation.

For sake of simplicity, the authors reported, in the following sections, the main choices concerning the material and methods taken into account during the experimental activities. More details are widely described in the authors' previous paper [13].

\subsection{MFC design and development}

The investigated stacked MFCs consist of 4 singlechamber reactors operating in batch mode and fluidically isolated, i.e., fed from individual lines.

They have been manufactured by using the Poly-Lactic Acid (PLA)-based material and a 3D printer (Delta Wasp 20x40) [14], downstream the definition of their shape and design by using the CAD support.

Each MFC shows a cubic shape with an internal volume of $28 \mathrm{~mL}$. Table 1 summarizes the main geometric parameters of each reactor.
Table 1. Geometric parameters of a single-chamber MFC

\begin{tabular}{|c|c|c|}
\hline Geometric details & Units & Values \\
\hline $\begin{array}{c}\text { External Dimensions } \\
\text { (length x height x depth) }\end{array}$ & $\mathrm{mm}$ & $50 \times 50 \times 46.5$ \\
\hline $\begin{array}{c}\text { Internal Dimensions } \\
\text { (diameter x depth) }\end{array}$ & $\mathrm{mm}$ & $30 \times 40$ \\
\hline Total internal volume & $\mathrm{mL}$ & 28 \\
\hline Cathode surface & $\mathrm{cm}^{2}$ & 7 \\
\hline
\end{tabular}

For each reactor, it has been selected a carbon fiber brush as anodic electrode and an activated carbon coated with both a PTFE (polytetrafluoroethylene) layer and a nickel mesh (as current collector) as cathodic one $[9,15]$.

\subsection{Substrate preparation, biofilm growth and bacteria acclimation}

The substrate used for feeding the MFCs consists of a mixture containing $50 \mathrm{~mL}$ of sodium acetate $1 \mathrm{M}$ and a mineral solution, prepared according to ref [16]. Sodium acetate ensures the highest energy yield for supporting the metabolism of exo-electrogenic bacteria if compared to fermentable compounds like glucose, lactose, starch and sucrose $[15,17]$. For avoided criticism to the catabolic activities of anaerobic bacteria, it has been needed to verify that the $\mathrm{pH}$ of the prepared substrate ranged from $7-8$, since it strongly affects the microorganisms' growth.

The biofilm selected in this study consists of endogenous bacterial species of the Compost, that generally are Bacillus, Geobacillus and Brevibacillus [18-20].

As concern the biofilm growth and the bacteria acclimation, a procedure consisting of 4 steps have been applied as detailed in [13].

\subsection{MFC electrical transient modeling}

Transient analysis for MFCs is very important since the current and the voltage values to evaluate the performance with polarization curves and to make power density analysis should be taken when pseudo-steady-state conditions have been established [21]. This condition can take several minutes or more.

The estimation of electrical voltage and currents during transient in MFCs operation can be made using proper models that allow the development of equivalent circuits able to emulate behavior of MFC in electrical network dynamic conditions.

In this paper, a simple model for the estimation of the electrical transient is proposed, according to the general solution of the step response of a first-order system:

$$
x_{1}(t)=c_{0}^{\prime}+c_{2}^{\prime} e^{-\frac{t}{\tau}}
$$

which can represent either a decreasing variable $\left(c_{0}^{\prime}=0\right)$ or an increasing variable $\left(c_{0}^{\prime}=-c_{2}^{\prime}\right)$.

An estimation of the biochemical transient is instead proposed through a simple linear function: 


$$
x_{2}(t)=c_{0}^{\prime \prime}+c_{1}^{\prime \prime} t
$$

Therefore, assuming the superposition principle, the entire transient pattern can be modelled through the following equation:

$$
x(t)=x_{1}(t)+x_{2}(t)=c_{0}^{\prime}+c_{2}^{\prime} e^{-\frac{t}{\tau}}+c_{0}^{\prime \prime}+c_{1}^{\prime \prime} t
$$

where the parameters $c_{0}^{\prime}, c_{2}^{\prime}, c_{0}^{\prime \prime}, c_{1}^{\prime \prime}, \tau$ are estimated through the minimum least-square approach on the measured sample data $x_{1}, \ldots, x_{N}$ :

$$
\begin{aligned}
& \min _{c_{0}^{\prime}, c_{2}^{\prime}, c_{0}^{\prime \prime}, c_{1}^{\prime \prime}, \tau} \sum_{n=1}^{N}\left[x_{n}-x\left(t_{n}\right)\right]^{2}= \\
& =\sum_{n=1}^{N}\left[x_{n}-c_{0}^{\prime}-c_{2}^{\prime} e^{-\frac{t_{n}}{\tau}}-c_{0}^{\prime \prime}-c_{1}^{\prime \prime} t_{n}\right]^{2} \\
& \text { s.t. } \\
& \quad c_{0}^{\prime}\left(c_{0}^{\prime}-c_{2}^{\prime}\right)=0 \\
& \quad \tau>0 .
\end{aligned}
$$

\section{Test Bench}

In order to assess the performance MFCs, an experimental test bench has been developed. It includes different devices to perform accurate measurements of MFCs voltage and current. In particular, it consists of a resistance box and four multimeters.

The resistance box allows changing the electrical load to which one or more reactors are connected. The 8-digit wheel switch allows to change the resistance value and the multiple gold contact arrangement ensures low contact resistance. The multimeters consist of an alphanumeric display, an input connector and a digital viewer, and allow measuring the instantaneous values of the current and of the voltage that are recorded on a dedicated computer. Fig. 1 shows the test bench set up in the laboratory.

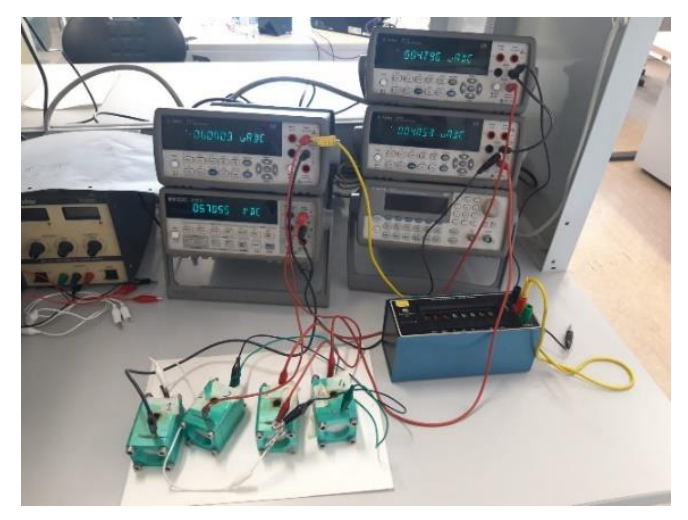

Figure 1. Test bench set up

\section{MFC Configuration}

In this paper two stacked configurations have been designed, developed, and tested. In the first configuration four MFCs have been connected in series mode, the second one, instead, in parallel-series mode. The performances in terms of volumetric power density (normalized with respect to the total volume of reactors) and electric power production for these configurations have been estimated and compared.

\subsection{Series Configuration}

Fig.2 shows the electrical circuit of the series configuration. It should involve an increase of the output voltage if compared to a single cell, since the output voltage is equal to the sum of four single-reactor output voltages.

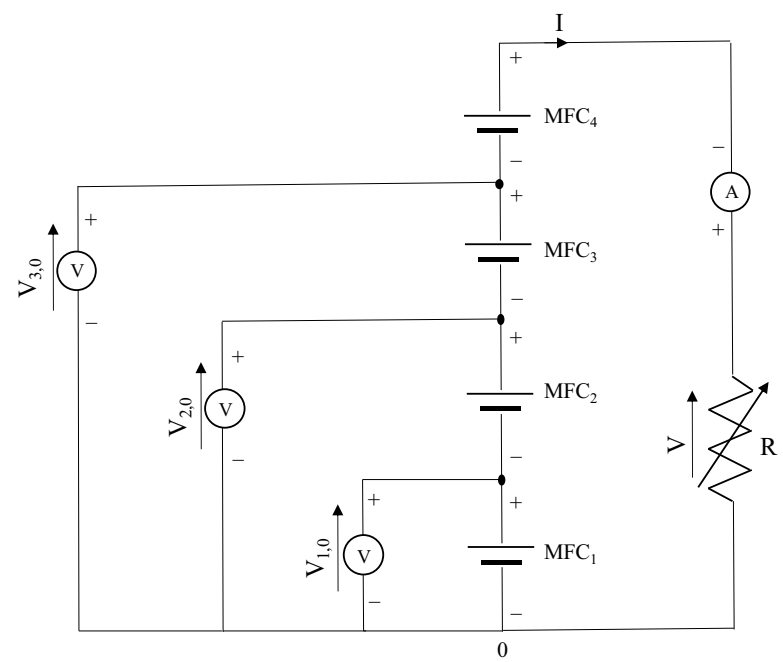

Figure 2. Electrical circuit of the series configuration

According to this electrical circuit, the test bench has been set up with three multimeters for the instantaneous voltage measurements $\left(V_{i, 0}\right.$ with $\left.i=1,2,3\right)$, and a multimeter for measuring the instantaneous value of the current $I$ flowing through the resistance. The voltage output of the $\mathrm{MFC}_{1}$ has been the one measured directly, while the output voltages for the $\mathrm{MFC}_{2}$ and $\mathrm{MFC}_{3}$ have been calculated according to the following equations:

$$
\begin{gathered}
V_{1}=V_{1,0} \\
V_{2}=V_{2,0}-V_{1,0} \\
V_{3}=V_{3,0}-V_{2,0}
\end{gathered}
$$

Note the value of the applied load resistance $R$ and the corresponding measured current $I$, it is possible to calculate the series stack output voltage as:

$$
V=R I
$$

where the resistance selected for this configuration ranged from $3.28 \mathrm{k} \Omega$ to $132 \mathrm{k} \Omega$ with variable steps. Eventually, the output voltage of $\mathrm{MFC}_{4}$ has been calculated by difference:

$$
V_{4}=V-V_{3,0}
$$




\subsection{Parallel-Series Configuration}

Fig. 3 illustrates the electrical circuit of the parallel-series configuration. It has been realized by connecting two MFCs in parallel mode and then by connecting two parallel connections in series mode. This configuration should involve an increase of the output current as well as of the output voltage if compared to a single cell.

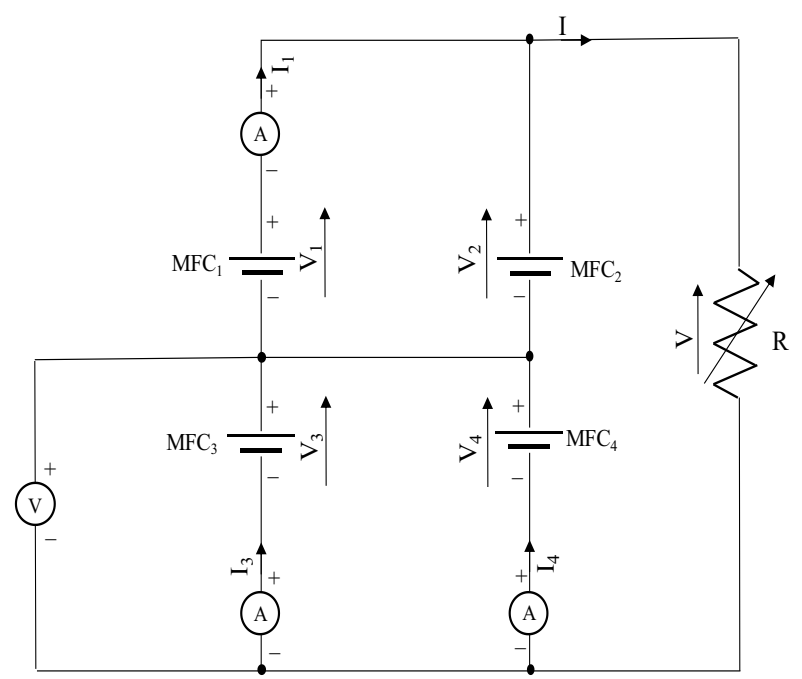

Figure 3. Electrical circuit of the parallel-series configuration

Based on this configuration, the test bench has been set up with three multimeters for measuring the instantaneous currents and a multimeter for the voltage measurement. This test bench allows to measure directly the currents of $\mathrm{MFC}_{1}, \mathrm{MFC}_{3}$ and $\mathrm{MFC}_{4}$, i.e. $I_{1}, I_{3}$ and $I_{4}$ and the voltage of the cell $\mathrm{MFC}_{3}$, i.e. $V_{3}$, which is equal to $V_{4}$ because of the parallel connection of $\mathrm{MFC}_{3}$ and $\mathrm{MFC}_{4}$. The other electric quantities have been calculated according to the following equations:

$$
\begin{gathered}
I_{2}=I_{3}+I_{4}-I_{1} \\
I=I_{3}+I_{4}=I_{1}+I_{2} \\
V_{1}=V_{2}=R\left(I_{3}+I_{4}\right)-V_{3}
\end{gathered}
$$

where the resistance selected for this configuration ranged from $1.64 \mathrm{k} \Omega$ to $66 \mathrm{k} \Omega$ with variable steps.

\section{MFC testing activity}

For comparing the performances of the proposed MFCs configurations, the experimental activity has been organized in three tests:

- Test 1: the polarization curves for each configuration have been performed at the end of the acclimation phase. In particular, the polarization curves have been carried out starting from the monocyclic method reported in ref. [22], which consists of applying decreasing values of resistances, each one supplied for a time interval of 9 minutes. The electrical quantities are measured with a sampling time of $1 \mathrm{~s}$. For each test obtained with a value of resistance, the average value of stack output voltage is calculated.

- Test 2: the transient patterns of the measured currents and voltages are analyzed and characterized through the procedure described in Section 2.3. The time period considered for each analysis is of 9 minutes, i.e., the same length of the acquisition of Test 1. Only for sake of conciseness, the analysis and characterization of the transient current and voltage patterns are presented in this paper for the acquisitions corresponding to the maximum volumetric power densities of the parallel-series configuration and of the series configuration, determined by Test 1 .

- Test 3: the polarization curves for each configuration have been performed considering an "inverse monocyclic method". It consists in applying increasing values of resistances, each one supplied for a time interval of 9 minutes. The electrical quantities are measured with a sampling time of $1 \mathrm{~s}$. For each test obtained with a value of resistance, the average value of stack output voltage is calculated.

\section{Results}

Before estimating the performance of the series and the parallel-series configurations, the performance of a single cell, in terms of polarization and power density curves, has been evaluated.

\subsection{Single Cell Performance}

Fig. 4 shows the polarization curve and the volumetric power densities measured for the single MFC. The volumetric power density has been calculated taking normalizing the produced electric power with respect to the MFC internal volume, which is equal to $28 \mathrm{~mL}$. It can be noticed that the average current is in the range 0.01 $0.03 \mathrm{~mA}$ and the average voltage ranges from 0.02 to 0.33 $\mathrm{V}$. The maximum average volumetric power density is 131 $\mathrm{mW} / \mathrm{m}^{3}(3.66 \mu \mathrm{W})$ at $0.023 \mathrm{~mA}$.

For the single cell, at high current densities the "power overshoot" occurs. This phenomenon refers to a "doubling back" effect of the power density curve in which a lower power than that measured for lower current densities is measured [23]. It is mainly due to the increase of internal resistance and also to the inability of bacteria (on the anode) of producing sufficient current at lower voltages [24]. 


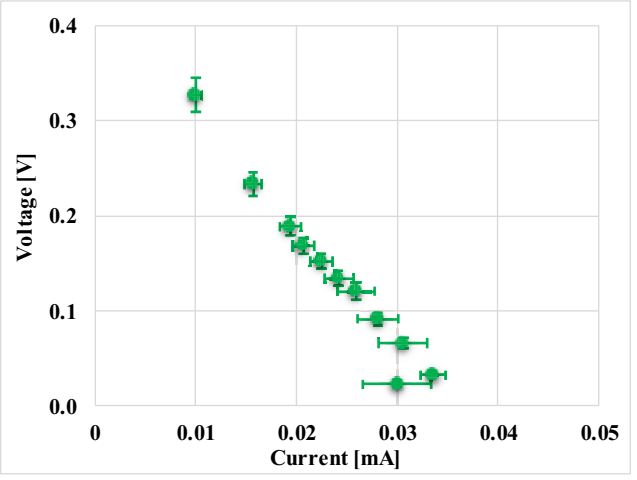

(a)

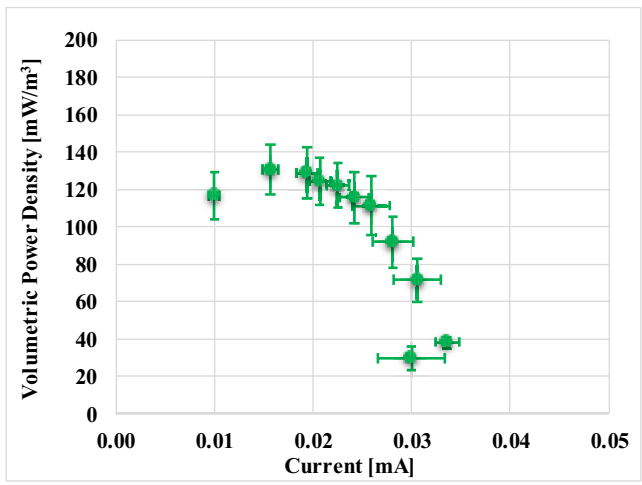

(b)

Figure 4. Polarization (a) and volumetric power density (b)curves of the single MFC

\subsection{Behavior and performance in Test 1}

Test 1 has involved the measurement and the comparison of the performances for the series and the parallel-series configurations in terms of polarization and power density curves (Fig.5). It is worth noticing that the parallel-series configuration reaches the best performance in terms of volumetric power density, producing $787.8 \mathrm{~mW} / \mathrm{m}^{3}(88.2$ $\mu \mathrm{W})$ at $0.21 \mathrm{~mA}(0.419 \mathrm{~V})$, by applying an external resistance of $2 \mathrm{k} \Omega$. Even if the series configuration allows to have the highest voltage operating range (up to $2 \mathrm{~V}$ ) compared to the parallel-series configuration, the maximum volumetric power density is $543.4 \mathrm{~mW} / \mathrm{m}^{3}(60.9$ $\mu \mathrm{W}$ ) at $0.05 \mathrm{~mA}$, by applying an external resistance of 22.4 $\mathrm{k} \Omega$. The calculated standard deviations of the maximum power densities are equal to $\pm 114.44 \mathrm{~mW} / \mathrm{m}^{3}$ and \pm 106.02 $\mathrm{mW} / \mathrm{m}^{3}$ for the parallel-series and series configurations, respectively.

It is important to highlight that the obtained performances, for both configurations, are lower compared to the ones obtained in the authors' previous paper $\left(2451 \mathrm{~mW} / \mathrm{m}^{3}\right.$ and $1799 \mathrm{~mW} / \mathrm{m}^{3}$ for the parallel-series and the series configuration, respectively)[13]. In particular, that the performance, in terms of produced volumetric power density decreases of about $67.9 \%$ and $69.8 \%$ for the parallel-series and series configuration, respectively. These lower performances are certainly due to the aging of the cathodes, since these tests have been carried out 5 months later

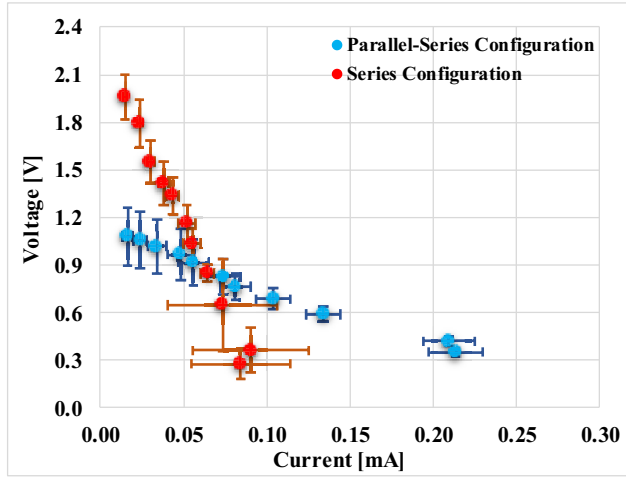

(a)

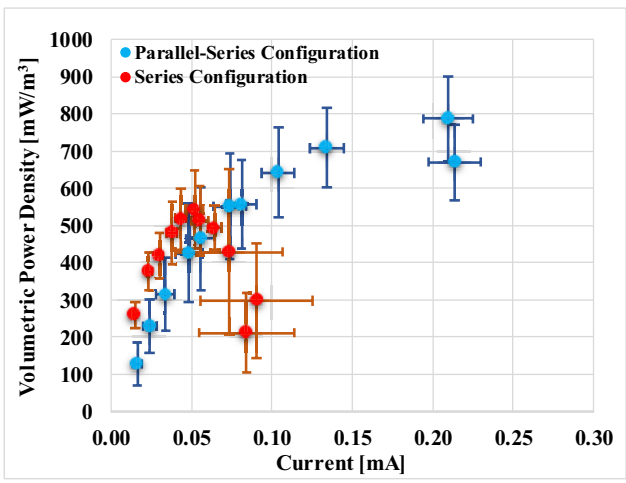

(b)

Figure 5. Polarization (a) and volumetric power density (b) curves for series and parallel-series configuration

\subsection{Behavior and performance in Test 2}

Test 2 involves the analysis and characterization of the transient patterns of the current and voltage measured for each reactor, through the procedure described in Section 2.3. Only for sake of conciseness, the results presented here are related only to two acquisitions that correspond to the maximum volumetric power densities of the parallelseries configuration (i.e., $2 \mathrm{k} \Omega$ resistance load) and of the series configuration (i.e., $22.4 \mathrm{k} \Omega$ resistance load).

Figs. 6 and 7 show the currents and voltages versus time measured for the parallel-series and series configurations, respectively. It can be noticed that the electrical variables measured on each MFC follow both a purely electrical transient and a "biological transient" (much slower) due to the capability of bacteria to adapt themselves for delivering current under the new load conditions. In the parallel-series configuration (Fig. 6), voltages drop by about $12-14 \%$ in the first 100 seconds, whereas all currents except $I_{1}$ drop by about $4-16 \%$ in the first 100 seconds; current $I_{1}$ follows instead an initial rise $(\sim 8 \%)$ in the first 100 seconds, and a subsequential drop. In the series configuration (Fig. 7), voltages drop instead by less than $4 \%$ in the first 100 seconds, and the current drops by about $4 \%$ in the first 100 seconds. In both configurations, about $50 \%$ of the total variation of the variable that can be evidenced in the 9-minutes interval occurs in the first $\sim 50$ seconds. 

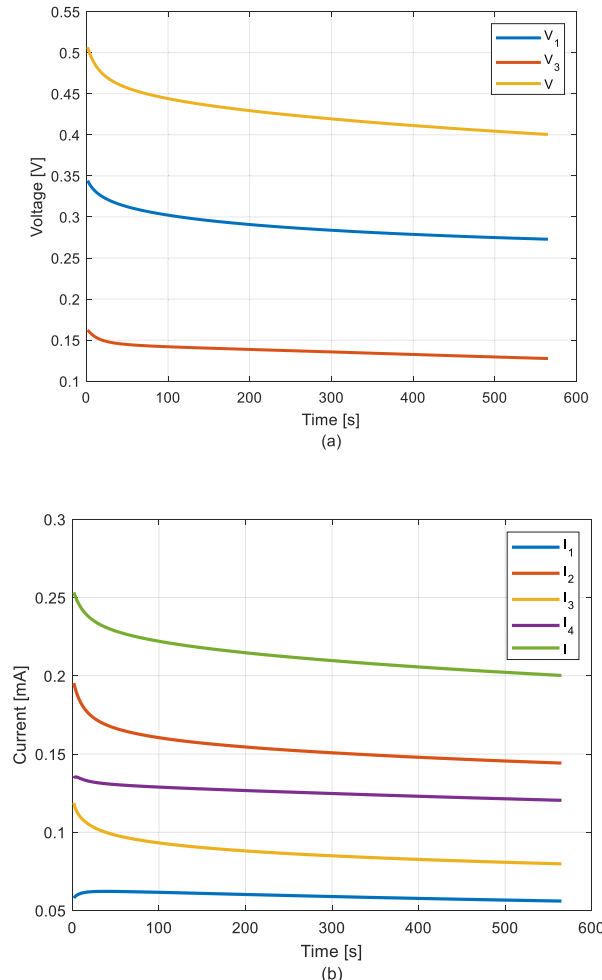

Figure 6. Voltages (a) and currents (b) versus time measured during the polarization experiment in test 1 for the parallelseries configuration
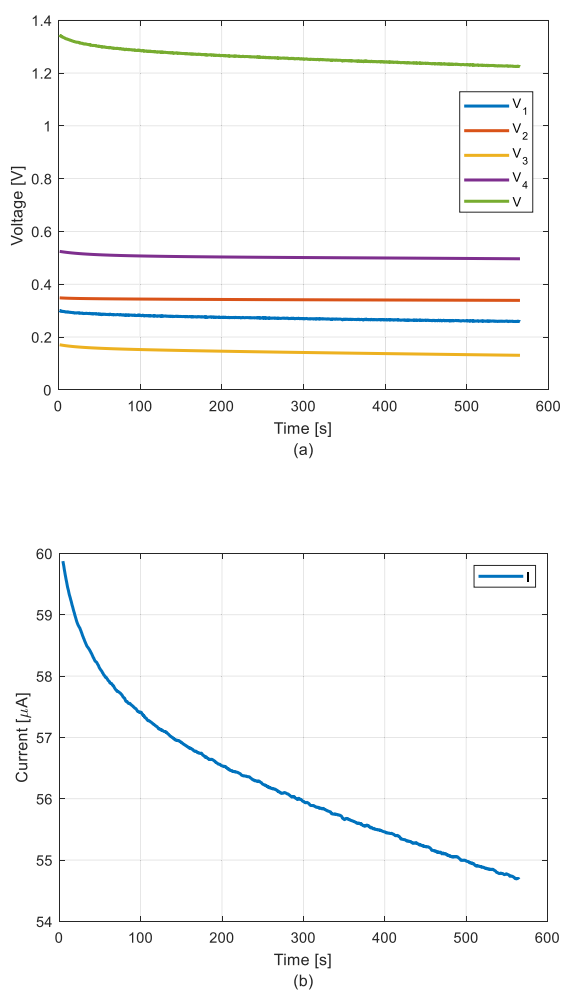

Figure 7. Voltages (a) and current (b) versus time measured during the polarization experiment in test 1 for series configuration

As an example of the estimation procedure of the electrical quantities, described in Section 2.3, the voltage and current estimations for the parallel-series configuration are reported in Fig. 8. In particular, the comparison between the measured and the estimated voltages and currents for the $\mathrm{MFC}_{1}$, selected between the reactors of the parallelseries configuration (by applying the load resistance at which the maximum volumetric power density is reached), is depicted. From the graphical inspection of Fig. 8, it appears that the proposed transient model allows obtaining a good approximation of the actual pattern, although further improvements could be obtained using more complex models, especially for the tails of the pattern.
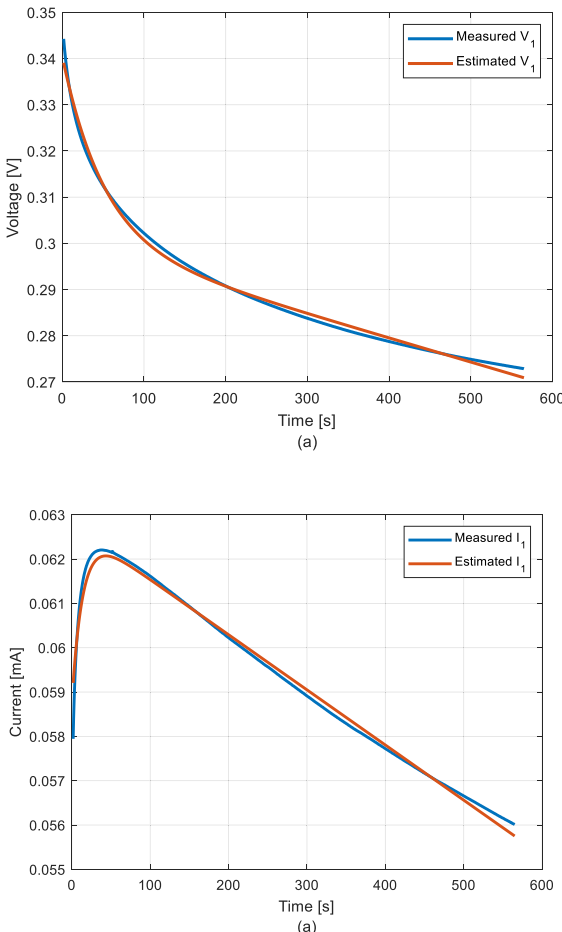

Figure 8. Comparison between the estimated and measured voltages (a) and currents (b) versus time for $\mathrm{MFC}_{1}$ in the parallelseries configuration.

Although not reported here, for sake of conciseness, good results in terms of transient approximation are achieved also in the series configuration. Table 2 eventually summarizes the values of the parameters estimated according to eq. (4) for the parallel-series and series configuration.

Table 2. Estimated parameters

\begin{tabular}{|c|c|c|c|c|}
\hline \multirow{2}{*}{ Parameter } & \multicolumn{2}{|c|}{$\begin{array}{c}\text { Parallel-series } \\
\text { Configuration }\end{array}$} & \multicolumn{2}{c|}{$\begin{array}{c}\text { Series } \\
\text { Configuration }\end{array}$} \\
\cline { 2 - 5 } & Voltage $V_{1}$ & Current $I_{1}$ & Voltage $V_{1}$ & Current $I$ \\
\hline$c_{0}^{\prime}$ & 0 & 0 & 0 & 0 \\
\hline$c_{2}^{\prime}$ & 0.040 & -0.004 & 0.016 & 0.003 \\
\hline$c_{0}^{\prime \prime}$ & 0.300 & 0.063 & 0.238 & 0.047 \\
\hline$c_{1}^{\prime}$ & $-5.218 \times 10^{-5}$ & $-1.244 \times 10^{-5}$ & $-4.269 \times 10^{-5}$ & $-4.653 \times 10^{-5}$ \\
\hline$\tau$ & 50.519 & 13.723 & 80.059 & 64.202 \\
\hline
\end{tabular}




\subsection{Behavior and performance in Test 3}

The test 3 has allowed measuring the polarization curves by applying the "inverse monocyclic method". It consists in applying increasing resistances and thus in evaluating the rectors' behaviors switching from higher to lower values of produced output currents. Fig. 9 compares the performances in terms of polarization and power density curves by applying the "inverse monocyclic method" for the tested configurations.

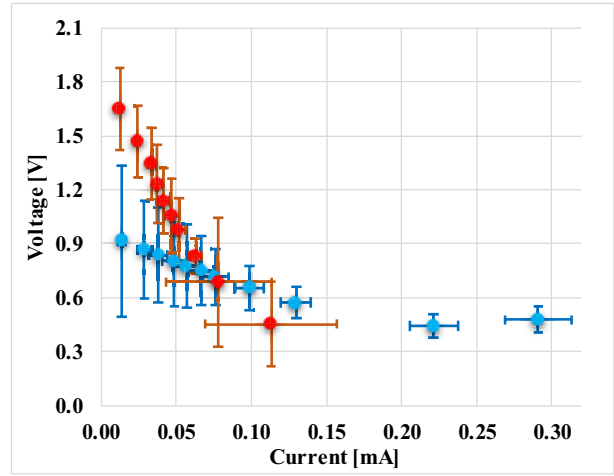

(a)

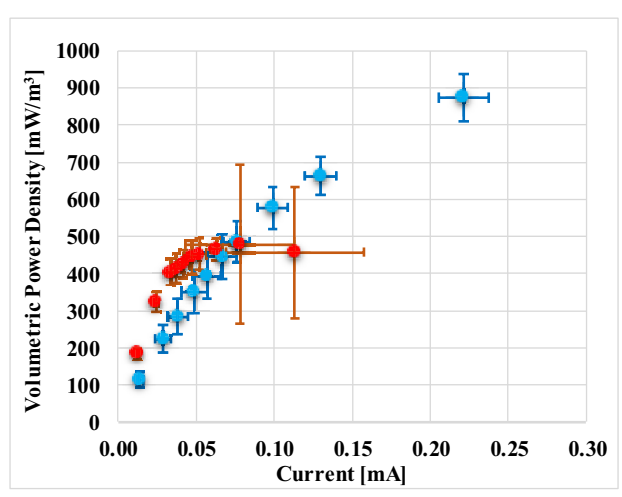

(b)

Figure 9. Inverse polarization (a) and volumetric power density (b) curves for series and parallel-series configuration.

It is worth noticing that also applying the "inverse monocyclic method" the parallel-series configuration reaches the best performance in terms of volumetric power density. Besides, by comparing the results for the test 1 and test 3 , it is highlighted that:

- the power overshoot occurs for the series configuration but not for the parallel-series one;

- the current reversal does not occur for the seriesconfiguration, unlike what happens in the test 1 ;

- the parallel-series configuration, has shown the best volumetric power density, $1248.5 \mathrm{~mW} / \mathrm{m}^{3}$ $(139.8 \mu \mathrm{W})$ at $0.291 \mathrm{~mA}(0.477 \mathrm{~V})$, by applying an external resistance of $1.64 \mathrm{k} \Omega$;

- for the series configuration, the maximum volumetric power density is $478.8 \mathrm{~mW} / \mathrm{m}^{3}(53.6$ $\mu \mathrm{W})$ at $0.078 \mathrm{~mA}(0.687 \mathrm{~V})$, by applying an external resistance of $8.8 \mathrm{k} \Omega$. This value is lower compared to that measured during the test 1 ;

- the calculated standard deviations of the maximum power densities are equal to \pm 94.62 $\mathrm{mW} / \mathrm{m}^{3}$ and $\pm 215.10 \mathrm{~mW} / \mathrm{m}^{3}$ for the parallelseries and series configurations, respectively.

\section{Conclusion}

In this study, two stacked MFCs configurations, based on different electrical connection modes, have been designed, developed, realized, and tested. The analyzed configurations consist of 4 MFCs connected in series and parallel-series modes.

Three different tests have been carried out for both the configurations. Results highlighted that the parallel-series configuration assures the highest volumetric power density with respect to the series configuration, reaching the maximum volumetric power density, $1248.5 \mathrm{~mW} / \mathrm{m}^{3}$ $(139.8 \mu \mathrm{W})$ at $0.291 \mathrm{~mA}$, during the test 3 .

However, both in test 1 and test 3 , the reached performances in terms of volumetric power density for the series and the parallel series configurations significantly exceed those obtained for the single cell. As matter of fact, in test 1 the volumetric power densities of series and parallel-series configuration are 6 and 4-fold higher with respect to the single cell, respectively. In test 3 , instead, the volumetric power densities are 9.5 and 3.7-fold higher with respect to the single cell, for the parallel-series configurations, respectively.

Moreover, another result has been come out. In particular, the authors noticed that the obtained performances, for both configurations, were lower compared to the ones obtained in the authors' previous paper $\left(2451 \mathrm{~mW} / \mathrm{m}^{3}\right.$ and $1799 \mathrm{~mW} / \mathrm{m}^{3}$ for the parallel-series and the series configuration, respectively). As matter of fact, the produced volumetric power density, decreases of about $67.9 \%$ and $69.8 \%$ for the parallel-series and series configuration, respectively. These lower performances are certainly due to the aging of the cathodes, since these tests have been carried out 5 months later. This effect will be deeply analyzed in future studies.

\section{References}

1. M. A. Moqsud, K. Omine, N. Yasufuku, M. Hyodo, and Y. Nakata, Waste Manag. (2013)

2. D. Borello, G. Gagliardi, G. Aimola, V. Ancona, P. Grenni, G. Bagnuolo, G. L. Garbini, L. Rolando, and A. Barra Caracciolo, Int. J. Hydrogen Energy 46, 10131 (2021)

3. E. Casula, B. Kim, H. Chesson, M. Di Lorenzo, and M. Mascia, Electrochim. Acta 368, (2021)

4. M. Alaraj and J. Do Park, J. Power Sources 418, 
225 (2019)

5. G. Di Ilio and G. Falcucci, Int. J. Hydrogen Energy 46, 20280 (2021)

6. R. A. Nastro, N. Jannelli, M. Minutillo, M. Guida, M. Trifuoggi, L. Andreassi, A. L. Facci, V. K. Krastev, and G. Falcucci, Energy Procedia 105, 1102 (2017)

7. D. Frattini, G. Falcucci, M. Minutillo, C. Ferone, R. Cioffi, and E. Jannelli, Chem. Eng. Trans. (2016)

8. S. Cheng, H. Liu, and B. E. Logan, Environ. Sci. Technol. (2006)

9. M. Minutillo, R. A. Nastro, S. Di Micco, E. Jannelli, R. Cioffi, and M. Di Giuseppe, in E3S Web Conf. (2020)

10. E. B. Estrada-Arriaga, Y. Guillen-Alonso, C. Morales-Morales, L. García-Sánchez, E. O.

Bahena-Bahena, O. Guadarrama-Pérez, and F. Loyola-Morales, Water Sci. Technol. (2017)

11. I. Ieropoulos, J. Greenman, and C. Melhuish, Int. J. Energy Res. (2008)

12. Z. Wang, Y. Wu, L. Wang, and F. Zhao, Chinese Sci. Bull. 59, 2214 (2014)

13. M. Minutillo, S. Di Micco, P. Di Giorgio, G. Erme, and E. Jannelli, Energies 14, 5116 (2021)

14. S. Ford and M. Despeisse, J. Clean. Prod. (2016)

15. B. Logan, S. Cheng, V. Watson, and G. Estadt, Environ. Sci. Technol. (2007)

16. H. Liu, R. Ramnarayanan, and B. E. Logan,
Environ. Sci. Technol. (2004)

17. C. Gonzalez-Solino, E. Bernalte, B. Metcalfe, D. Moschou, and M. Di Lorenzo, J. Power Sources 472, 228530 (2020)

18. F. Flagiello, E. Gambino, R. A. Nastro, and C. Kuppam, in edited by P. Kumar and C. Kuppam (Springer Singapore, Singapore, 2020), pp. 217234

19. B. Cercado, N. Byrne, M. Bertrand, D. Pocaznoi, M. Rimboud, W. Achouak, and A. Bergel, Bioresour. Technol. (2013)

20. B. Cercado-Quezada, M. L. Delia, and A. Bergel, J. Appl. Electrochem. (2010)

21. B. E. Logan, B. Hamelers, R. Rozendal, U. Schröder, J. Keller, S. Freguia, P. Aelterman, W. Verstraete, and K. Rabaey, Environ. Sci. Technol. (2006)

22. V. J. Watson and B. E. Logan, Electrochem. Commun. (2011)

23. F. Khaled, O. Ondel, and B. Allard, J. Power Sources (2016)

24. B. Kim, J. An, and I. S. Chang, ChemSusChem (2017) 